\title{
Cluster Performance Reconsidered: Structure, Linkages and Paths in the German Biotechnology INDUSTRY, 1996-2003**
}

\begin{abstract}
We examine the evolution of biotechnology clusters in Germany between 1996 and 2003, paying particular attention to their composition in terms of venture capital, basic science institutions, and biotechnology firms. Drawing upon the significance of co-location of "money and ideas", the literature stressing the importance of a cluster's openness and external linkages, and the path dependency debate, we analyze how certain cluster characteristics correspond with each cluster's overall performance. After defining different cluster types, we explore and compare the clusters' internal and external interconnectivity, and investigate the extent to which the clusters' structural composition has changed over time. Our results indicate that the structure, i.e., the type of cluster, and the cluster's openness towards receiving external knowledge provide merely unsystematic indications of a cluster's overall success. The cluster's ability to modify its composition to a more balanced ratio of science and capital over time, in contrast, turns out to be a key explanatory factor.
\end{abstract}

JEL-Classification: L22, 018, O32.

Keywords: Basic Science; Biotechnology; Cluster Evolution; Dynamic Perspective; Germany; Venture Capital.

* Carolin Häussler, Institute for Innovation Research, Technology Management, and Entrepreneurship; HansMartin Zademach, Institute of Economic Geography, both Ludwig-Maximilian University of Munich, e-mail: haeussler@lmu.de and zademach@lmu.de.

** The authors are grateful to Dietmar Harhoff, Lars Ullerich, the participants of the session Corporate Strategy, Innovation, and Technology Paths at ACCS 2006, as well as the anonymous referees for insightful comments on earlier versions of this paper. Furthermore, we thank Dominik Rodler for competent research assistance. Financial support provided by the German Research Foundation (SfB Transregio 15 for C. Häussler and HA 795/8-1 for H.-M. Zademach) and the Fritz Thyssen Stiftung is gratefully acknowledged. 


\section{INTRODUCTION}

There is a long and well-established tradition of regarding clusters, industrial districts, or regional innovation systems as favored locations for the production of goods, services, and knowledge (e.g., Audretsch and Feldman (1996); Bresnahan et al. (2001)). One side argues that firms, industries, and knowledge are becoming more and more footloose and that more and more often economic activities take place regardless of physical distance. In such a "weightless economy" (Quah (1997); Coyle (1997)), geography is treated more or less as an historical relict (Ohmae (1990); Cairncross (1997)). Another side follows a radically different line of thinking. According to this second view, spatial proximity enhances the competitiveness of firms by facilitating the types of interrelations and interactions that keep organizations in place. Proximity fosters the processes of learning and innovation by means of face-to-face contacts, "local buzz", localized capabilities, and the like (e.g., Maskell and Malmberg (1999); Storper and Venables (2004)). According to this line of reasoning, proximity acts as a basic governance mechanism, because it reduces transaction costs by establishing helpful local codes and a common language. In a similar vein, Morgan (2004) warns before an uncritical acceptance of the "death of geography" hypothesis, since knowledge creation still depends on localized interaction. Thus, a specific geographical configuration of economic activity is regarded as being crucial in shaping the future prospects of firms and industries (compare also Zademach (2005)).

Many of the characteristics of the knowledge-intensive sectors support this line of argument. According to Leamer and Storper (2001), these sectors, although they permit a decentralization of certain routine activities, contribute to reinforcing urban concentration and agglomeration. Economic success in the knowledge-intensive services often hinges on the creation of networks, on social interaction, locally based tacit knowledge, and personal contacts, factors whose genesis depends significantly on geographical closeness (e.g., Rodríguez-Pose and Zademach (2006)). As a spatial expression of this phenomenon, the emergence of strong clustering effects, such as the concentration of high-technology industries in California's Silicon Valley, the Boston and Cambridge areas in Massachusetts, and in India's Bangalore, are found all around the globe. However, discussions about the cluster phenomenon concentrate on only a handful of famous clusters. Several locations that start off with favorable conditions did not take off, but instead sank into oblivion. The concentration on the few successful clusters has led many researchers and policy analysts to almost a "recipe" approach: Take a university, locate some investors around it, initiate entrepreneurship lessons, and the cluster economies will start off.

In this paper we address the mechanisms that catapult regions to extraordinary performance. Building on Powell et al.'s (2002) work on the biotechnology industry in the U.S., in which they explore the relationship between science institutions, venture capital (VC), and biotechnology firms, and identify the significance of "co-location of money and ideas", we use the case of the biotechnology industry in Germany as testing ground.

Our analysis proceeds from a triad of conceptual starting points. First, we investigate the extent to which the clusters' composition (i.e., the proportion between locally based science and capital). Second, we examine their external linkages. Third, we analyze how 
their evolutionary trajectories correspond to their respective performance levels. That is, we do not only put emphasis on if, but also on how clusters change over time. We do so by looking at several clusters that show a wide heterogeneity of performance. We explore their configuration, their degree of openness and internal interconnectedness, and their structural transformation over time.

The paper proceeds as follows. In Section 2 we develop relevant theoretical considerations from the related literature. Section 3 briefly sketches the characteristics of the human biotechnology industry. In Section 4 we specify the methods of the analysis and present our empirical results. Section 5 concludes.

\section{Literature Review and Theoretical Considerations}

Studies in business and managerial science highlight that the composition of a cluster (Porter $(2000,254)$ ), i.e., its configuration in terms of private firms, public institutions, governmental regulations, access to capital, sectoral specifications, is crucial for providing a "cradle" for innovative firms (e.g., Feldman (1994)). For nurturing innovative firms, science and capital are two essential factors. Substantiating this statement, Powell et al. (2002) find that these two factors are strongly concentrated in regional U.S. hotspots of the biotechnology industry.

Given the at least theoretically unrestricted ubiquity of capital, we might question the basic rationales behind the spatial concentration of money and ideas. Here, a key rationale relates to the fact that in high-technology industries, innovations are the result of an accumulation and a special combination of knowledge in the basic and applied sciences. Public research institutes not only draw scientists and engineers to a region, but also generate knowledge that nearby firms can use. In her case study, Saxenian (1994) reports the importance of knowledge transfer between Stanford University and firms located in Silicon Valley. Jaffe (1989) shows that university research has a positive impact on patenting of firms in the same region. Feldman and Florida (1994) note that the clustering of innovations is related to the existence of R\&D institutions, universities, and firms in a particular region as main centers of knowledge creation. By the same token, Prevezer (1997) finds that the strength of the science base is an effective magnet for the entry of biotechnology firms in the U.S. (compare Audretsch and Stephan (1996); Zucker et al. (1998)).

A second key aspect is the availability of venture capital (VC), with its well-established role in the development of high-technology regions. The private equity market has grown at an explosive rate and is a major source of financing for start-up firms. Empirically, Powell et al. $(2002,304)$ find a strong pattern of spatial concentration in biotechnology and $\mathrm{VC}$, and state " $\ldots$ that without venture capital and regional agglomeration, the industry would not exist in the form that it does today". The role of locally based capital might appear astonishing at first sight, since money, particularly compared to knowledge, is highly fungible (Clark and Wójcik (2005)). Yet most venture or risk capital investors not only transfer the money, they also provide advice and contacts, and have a major influence in management decisions. Being able to combine the investment process with such 
influence is one of the distinctive features of venture and private equity capital. Because problems of asymmetric information, agency, and uncertainty are a function of physical distance (Porteous (1995)), the geographical proximity between firms seeking, and institutions providing, finance reduces the costs and efforts of monitoring and consulting. Thus, a spatially concentrated distribution of innovations and "smart money" may be seen as distinctly advantageous compared to more dispersed systems (Casamatta (2003)).

Following the argument of Bathelt et al. (2004), the co-location of money and ideas, however, cannot be regarded as the sole source of a regional innovation system's economic and innovative success. Instead, we must also take into account the role of external sources in stimulating growth within a cluster. In other words, besides local "noise" (Grabher (2002)) fed by the interconnection of local actors, so called "trans-local pipes" pump knowledge from other areas of the nation and the world into the cluster. These pipes are expected to be relevant for cluster success. The openness of the cluster is particularly important when the market for the innovation is global. Ties to market actors worldwide keep the cluster up to date and provide relations to current and potential collaborators in research and commercialization (Bresnahan et al. (2001); Zeller (2001)).

However, obtaining access to external information and partners over pipes often requires accepting high uncertainty and undertaking significant investment. Here, some institutions (e.g., government and investors) can play a decisive role, first by being the boundary spanners that build the bridge between clusters and non-local actors over which information flows to the cluster, and second by bringing to the cluster their experience from operating in other parts of the world. Apart from providing money, VC firms play a hands-on role in the running of the young companies and provide relevant sources of management expertise. Although it is generally acknowledged that these processes of monitoring, advising, and managing are much more easily accomplished when the young firm is located nearby, the mere focus on the local arena runs also the distinct risk of lock-in effects (e.g., Grabher (1993)). To avoid such lock-ins, "consciously open network relations for the influx of external information as well as maintaining a certain amount of distrust with respect to traditional solutions are important" (Bathelt et al. $(2004,42))$. The same mechanism holds for the firm level. Several studies show that biotechnology firms involved in an intense collaboration network bring products to the market faster (Rothaermel and Deeds (2004)), attract more capital (Stuart et al. (1999)), and are more likely to restructure in times of change (Häussler (2007)).

Third, we regard clusters as moving targets whose composition and interconnectivity evolve over time. Past cluster studies (at least those that compare multiple clusters) rarely consider the dynamics and trajectories of clusters as being relevant to their performance. However, the dynamic lens is gaining momentum with the accelerated pace of technological innovations and increased competition. Changes in the composition of clusters can be understood as an evolutionary path. These paths show the development of cluster characteristics, such as growth in number of firms, performance (e.g., patents, products), and structure (e.g., science and capital) over certain time spans. Based on the assumption that these paths are not fully dependent on their earlier positions, the actors in a cluster or third parties (e.g., government) can influence the paths. 
The composition of clusters over time may remain stable, or may show a trend towards greater convergence (respectively divergence). Several researchers provide convincing arguments (e.g., imitation is inherent in human nature, people exchange ideas, learn from each other, and may be influenced by the same advisors) which favor the convergence hypothesis (DiMaggio and Powell (1983); Häussler and Harhoff (2007)). Yet, this hypothesis has hardly ever been tested for cluster evolution. To our best knowledge, the most closely related study is Owen-Smith and Powell's (2006) comparative investigation of the Boston and San Francisco Bay Area clusters. By examining three types of ties - those between biotechnology firms, between biotechnology firms and investors, and between biotechnology firms and public research organizations - the authors show that the clusters network structure shows strong differences in 1994 but resembles in the year 1999. Broad similarities between clusters today "...can be outcome of divergent patterns of development" (p. 3). However, the authors focus only on two very successful clusters; hence, we cannot derive any general conclusion between evolutionary paths and cluster performance.

\section{Human Biotechnology Industry as Testing Ground}

The biotechnology industry was born when recombinant DNA technology and molecular genetics opened an innovative method of research. In this industry, it is widely recognized that firms tend to cluster for the following reasons. First, the biotechnology industry exemplifies many of the characteristics of all science-based sectors. Firms must be at the forefront of science to be successful market actors. Thus, biotechnology firms are often linked to universities and public research institutes that conduct basic and applied science. Second, biotechnology is likely to profit from local economies because much of its knowledge is tacit and uncodifiable (Aharonson and Feldman $(2004,3)$ ). Third, by its very nature, the R\&D process is highly uncertain and complex (Häussler (2005)). On average, during the ten to 15 years it takes to develop a drug and bring it to market, the 10,000 compounds that enter the process are narrowed down to one single marketable drug. Fourth, biotechnology firms are dependent on the capital market. Developing pharmaceutical products is highly capital intensive. On average, the costs to develop a new drug amount to $\$ 802 \mathrm{M}$ (DiMasi et al. (2003)). Thus, the availability of capital is an important ingredient for developing a seedbed for biotechnology firms.

In Germany, there were very few signs of a biotechnology industry when Interferon ${ }^{\mathrm{TM}}$, the first drug developed by a biotechnology firm, entered the market in 1986 . The amendment of the Genetic Engineering Act in 1993 significantly improved the administrative and legal environment for biotechnological research, raising hope for a biotechnology industry in Germany. The initial spark was the BioRegio competition in 1995 launched by the German Federal Ministry of Education and Research, which aimed to boost the foundations of biotechnology firms around its winner regions. Entrepreneurs in life sciences were motivated by public policy and enormous government subsidies to form ventures around those regions.

The German biotechnology regions provide an excellent environment for investigating the structure and evolutionary paths of biotech clusters. We begin our observation period in 
1996 in order to capture the effect of the BioRegio competition, the early steps of biotechnology firm foundation in Germany, and to track the development of biotechnology firms, science institutions and investors in biotechnology.

\section{Specification of Analysis and Empirical Results}

Before focus is shifted on the empirical results and the examination of the extent to which the given theoretical approaches help to explain the performance of German biotech clusters, we briefly describe the database and discuss our methods.

\subsection{Data, Methods and Cluster Identification}

Our main source for our investigation is a compilation of the annual BioCom ${ }^{1}$ listing of biotechnology firms, public institutes that perform biotechnology research, and investors in biotechnology that operated in Germany between 1996 and 2003. Further directories, e.g. Dechema or the Dufa-Index were used to complement the database. We also compiled separate data on risk/venture capitalists investing in biotechnology firms by using information from the magazines Venture Capital, Going Public and Transcript, the Venture Economics database, the VC Facts database, and from company press releases and announcements from the German Private Equity and Venture Capital Association.

To identify biotech clusters, the literature provides a variety of different approaches. They all offer more or less identical results, so that the "hot spots" of German biotech are well established (e.g., Ernst \& Young (2001); BioCom $(2004,13)$ ). On basis of our data record, these results are again substantiated. In our study, we identify clusters by using the relative Euclidean distances between biotechnology firms, research institutes, and VC investors in biotechnology. Applying a two-step approach, we first selected the raw cluster data from a map and then refined our selections analytically. Each firm's, each research institute's, and each VC investor's postal address was therefore converted into latitude and longitude measurements. Subsequently, we mapped the objects with help of MapInfo (a software package that offers a tool to identify clusters according to a selectable radius); clusters were specified as concentrations of an overall minimum of 40 objects, with the individual lower thresholds for firms, research institutes, and investors being 20, ten and two, respectively ${ }^{2}$. A clear leap in the quadratic distances from the cluster objects to the cluster center determines the borders of the clusters.

For each year during the period of investigation, this approach resulted in nine clusters in which a significant share of German biotechnology activities takes place in a spatially concentrated area $^{3}$. All nine regions are compact areas with radii ranging from $16.9 \mathrm{~km}$ (Hanover) to $60.7 \mathrm{~km}$ (Ruhr area). Beside these two areas, Hamburg, Berlin, Göttingen,

1 BioCom is the largest and most historical independently operating directory for biotechnology in Germany.

2 For a similar mean of cluster demarcation, see Aharonson et al. (2004).

3 Göttingen fulfills the given classification requirements only from 1999 onwards. 
the Rhine/Main area, and Heidelberg, as well as Stuttgart and Munich, come to the fore as the key nodes in German biotechnology. These areas all explicitly define themselves as a biotech region; the identification and interplay of the cluster participants is expressed, e.g., in an own logo and webpage that provides information on local firms, events, newsletters, and regular meetings. In all nine clusters, one institution was established (such as Bio-M and BIOPRO for Munich and Stuttgart, respectively) that fosters and bundles regional activities.

Despite these common characteristics, the evolution of the nine clusters varies significantly over time. Figures 1 and 2 indicate their differing levels of performance measured by the growth of the number of biotechnology firms located in each of the regions. Figure 1 depicts firm growth in absolute terms. Figure 2 refers to an index (setting 1996 to 100$)^{4}$.

\section{Figure 1: Performance of biotech clusters in Germany, 1996-2003 (measured in absolute number of firms per cluster)}

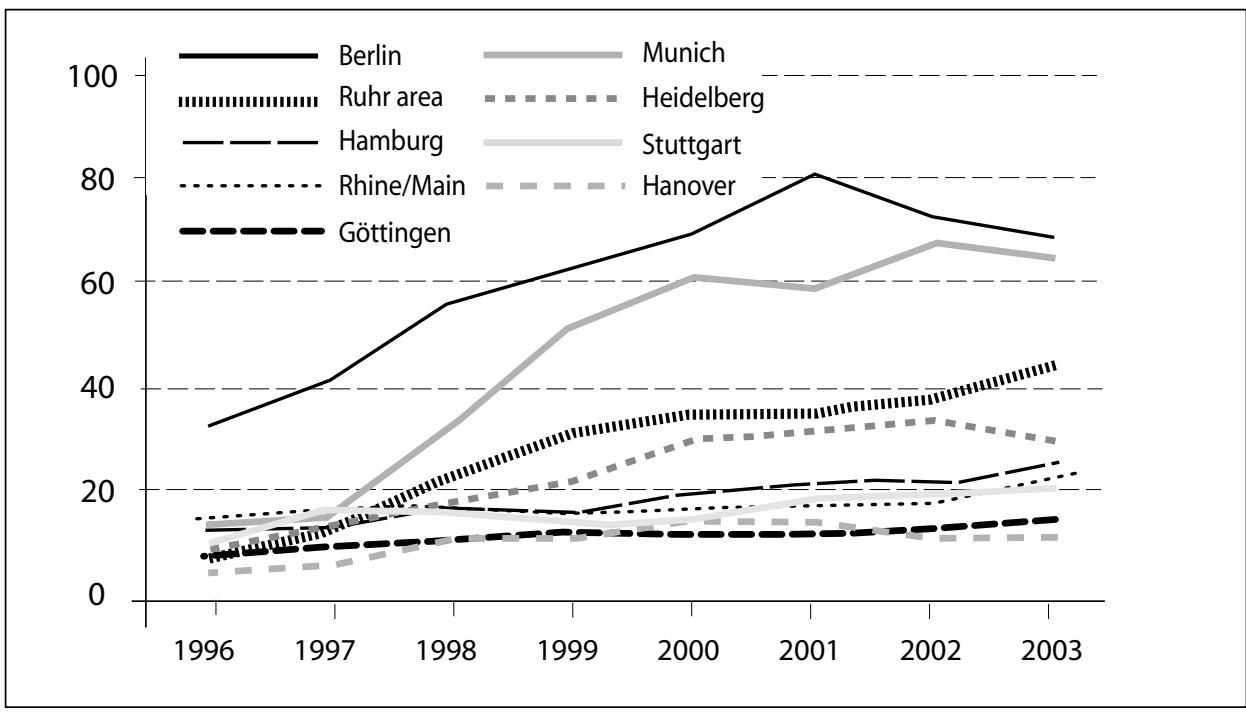

4 We realize that the sheer number of biotech firms represents a limited indicator to measure a cluster's overall performance. Therefore, we have controlled for the number of employees per firm in all clusters on the one hand, and the varying main fields of activity (e.g., mainly product firms vs. supplier and service firms) on the other. So far, we have not been able to observe any significant deviations compared to the chosen indicator. Nonetheless, we consider this an important field for future investigation. 


\section{Figure 2: Indexed performance of German biotech clusters, 1996-2003 (measured in relative firm growth per cluster; $1996=100$ )}

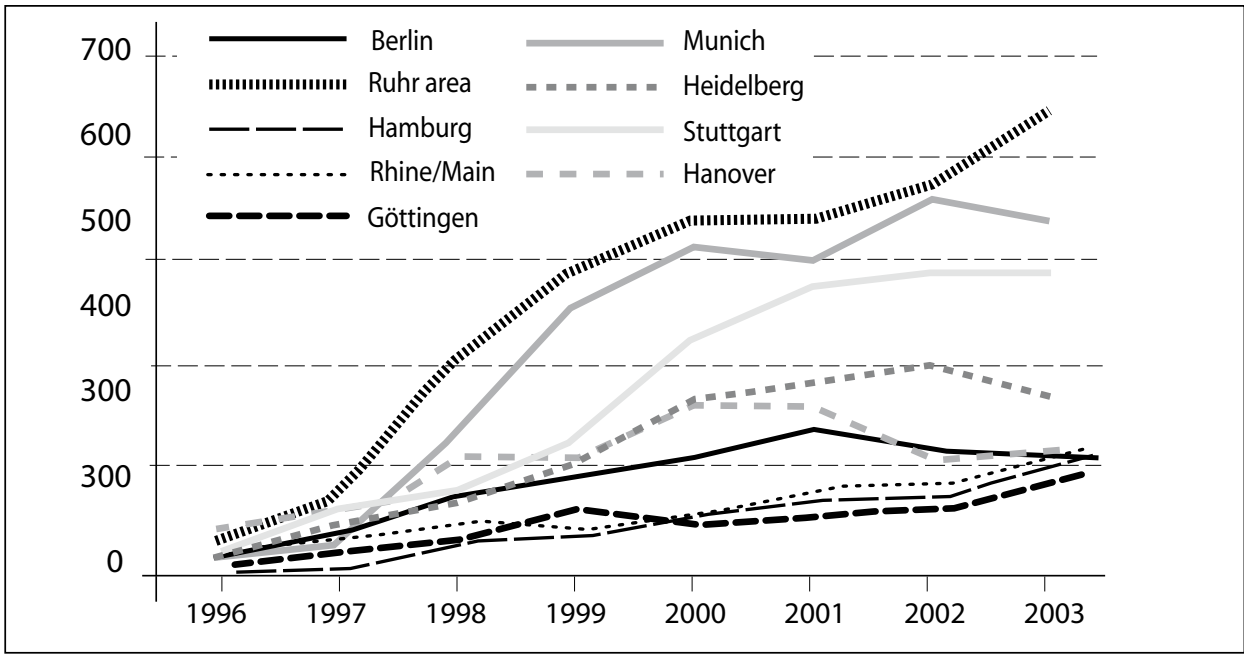

In both figures, Munich and the Ruhr area appear to outperform the other areas, as does Berlin, which shows in absolute terms the highest number of firms over the whole period of observation. Göttingen, Hanover, Hamburg, and the Rhine/Main area around Frankfurt display a below-average number of firms. To examine how the performance heterogeneity could be explained by the theoretical considerations, we use a three-step investigation. The first classifies the different clusters according to their composition. Here, the number of biotech firms is compared to the number of investors on the one hand, and to the number of basic science institutions on the other. By this means, we identify three different general cluster types: the well-balanced ones, the basic-science-driven ones, and the VC/investor-dominated ones.

The second step examines a cluster's openness and interconnection with the other clusters and also with firms located outside these key nodes. For this purpose, we use the amount of $\mathrm{VC}$ cash-flows and the number of VC investors that operated within and between the cluster objects, i.e., intra- vs. intercluster VC flows. In addition, this step of our analysis also covers the flows of public money and governmental subsidies, which must be regarded as important impulse transmitters that have a significant impact on a cluster's formation and evolution.

In the third step, we investigate the cluster's evolutionary trajectories by using an index that shows how a clusters composition changes over the period of investigation. The composition comprises two variables: the number of risk capital investors and number of basic research institutes. We calculate the Cluster Composition Index, $C C-I$, according to the following formula:

$$
C C-I=\frac{\Sigma B S_{i, t} / \Sigma V C_{i, t}}{\Sigma B S_{G e r, t} / \Sigma V C_{G e r, t}}
$$


$B S$ represents the absolute number of basic science institutions, $V C$ the number of risk capital investors or venture capitalists; $t$ denotes the year of investigation; $i$ stands for the included clusters; and Ger corresponds to the whole of Germany, i.e., the respective national total5.

Regarding the direction of change, we differentiate between clusters that shift towards a more balanced a structure and clusters that move towards a structure that strengthens their specific idiosyncrasies. The former direction points to convergence, the latter to divergence.

\subsection{Empirical Results I: Structure and Openness}

For the nine clusters, Figure 3 shows the total number of research institutes as a proxy for level of basic science on the abscissa, the total of VC investors as a measure for the amount of locally available risk capital on the ordinate, and the number of biotechnology firms via the size of the respective "bubble" with the total number in parentheses. The plot suggests a distinct degree of heterogeneity in the composition of clusters; however, some of them are obviously featured by rather similar characteristics.

Figure 3: Structural composition of German biotech clusters, 2003 (in absolute numbers)

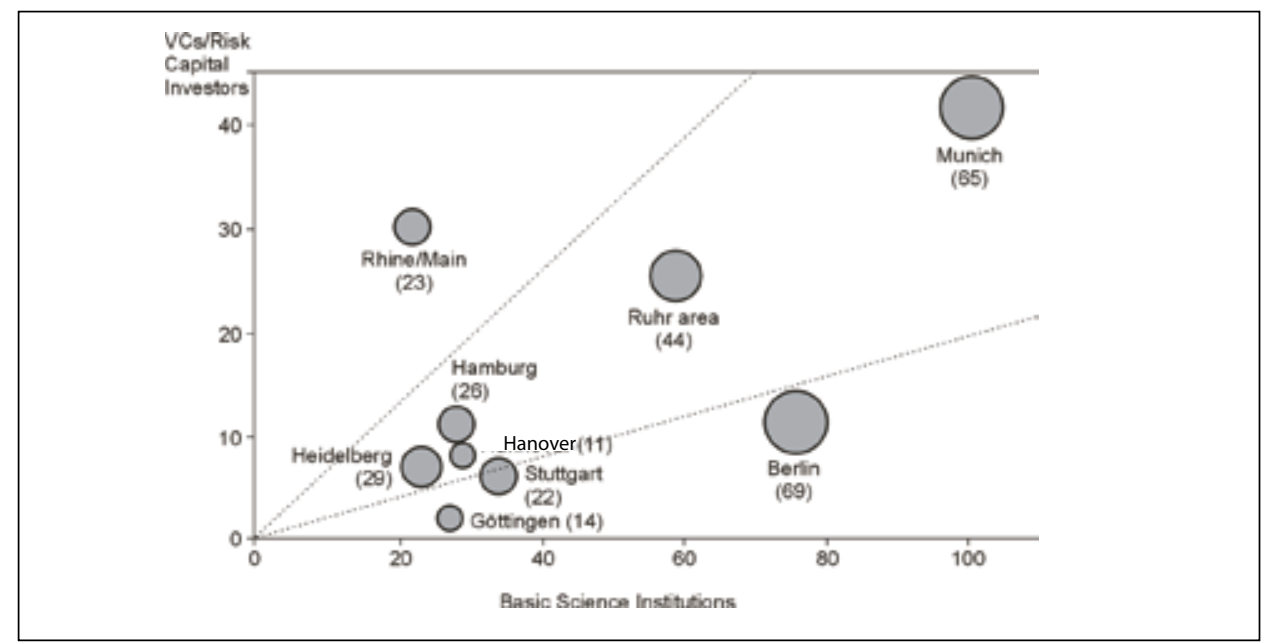

5 Via the standardization by the national average, the index controls for the overall proportion of investors and basic science institutions in the German biotechnology sector and thus covers the extent to which a cluster is relatively dominated either by 'ideas' or 'money'. An index below one indicates that the cluster hosts a larger proportion of investors compared to the national average. An index greater than one indicates that the cluster includes relatively more science institutions. 
As the most important locations of biotech production in Germany (compare also Figure 1, again), Munich and the Ruhr area display the greatest quantity of both science and capital. Likewise, the indexed rate of the firm growth (Figure 2) is highest in these two locations. In comparison, Hamburg, Hanover, Stuttgart, Heidelberg, and Göttingen have small numbers of research institutes and investors. The Rhine/Main area, with its financial center at Frankfurt, represents the second largest concentration of investors, but shows the smallest number of science institutions. The direct opposite is true for the capital city Berlin, which has a large number of science institutes but relatively few investors.

The exercise of depicting the cluster's composition in absolute terms gives a first idea of the varying types - "finance-driven" compared to more "science-dominated" compared to "well-balanced" clusters - that can be distinguished in the German biotechnology landscape. The Rhine/Main area around Frankfurt clearly represents the money-led player. Berlin, and to a lesser extent Göttingen, with Stuttgart as the borderline case, compose the contrasting group of the science-driven clusters (albeit in the case of the latter two, the crucial factor is a low number of investors rather than an extraordinary high number of science institutions). The remaining clusters of Munich, the Ruhr area, Hamburg, Heidelberg and Hanover are, at least at the end of the period of investigation, best captured as well-balanced in terms of their financial and scientific make-up.

When we contrast the varying cluster types with their performance, we cannot identify one dominant cluster type as particularly successful. The well-balanced and the sciencedominated clusters provide both above and below average performers alike. Similarly, Hanover, Göttingen, and the Rhine/Main area show a fairly dissatisfying performance, although they display entirely differing structural compositions. When we focus only on the three top performing clusters - Munich, Berlin, and the Ruhr area - we find that Munich and the Ruhr area belong to the well-balanced type, but shine out within this group by showing a particularly large number of research institutes and investors. The somewhat unbalanced Berlin area hosts a large number of research institutes, but locates only few investors. As an intermediate result, we note that no cluster type becomes apparent as clearly superior, and that a cluster's general composition adds only a little to explain its economic success.

In light of this finding, we now turn to the debate that stresses the importance of interconnectivity and external linkages. As far data availability allows, Table 1 reports the mean number of collaborations with nonprofit organizations (i.e., universities and research organizations) and for-profit firms for all biotechnology firms located in our nine clusters ${ }^{6}$. This distinction reveals information on the science versus technology orientation of the firms in the clusters. Companies that collaborate extensively with for-profit firms are presumably more oriented toward commercialization, whereas firms that collaborate with academic or nonacademic research organizations are more science intense and yet more distant from actually marketing their inventions. This exercise shows different levels of interconnectivity as well as distinct patterns of specialization. 
Table 1: Interorganisational collaborations of biotechnology firms, 2003

\begin{tabular}{lccc}
\hline & $\begin{array}{c}\text { Interorganisational } \\
\text { collaborations } \\
\text { Mean number per firm }\end{array}$ & Mean number of collaborations with \\
\hline Munich & 5.9 & $2.0(29)$ & for profit organisations \\
Hamburg & 5.2 & $0.7(9)$ & $3.9(28)$ \\
Berlin & 5.0 & $2.1(30)$ & $4.5(9)$ \\
Ruhr area & 4.2 & $2.1(17)$ & $2.9(30)$ \\
Hanover & 4.0 & $1.0(3)$ & $2.1(17)$ \\
Stuttgart & 3.9 & $1.6(7)$ & $3.0(4)$ \\
Rhine/Main & 3.8 & $1.3(4)$ & $2.3(7)$ \\
Heidelberg & 3.6 & $2.4(10)$ & $2.5(4)$ \\
Göttingen & 3.3 & $1.3(4)$ & $1.2(9)$ \\
\hline
\end{tabular}

Note: Number of observations in parentheses; based on data from BioCom (2003)

Among the group of the extensive collaborators are firms located in the three outperforming clusters - Munich, Berlin, Ruhr area - and in the low-performing Hamburg cluster. Hamburg is gaining attention as the cluster with the largest number of for-profit firms. This fact is presumably explained by a relative large proportion of service firms. In contrast, Heidelberg, with the largest number of pure product development firms, shows the largest number of collaborations with nonprofit organizations, but a low number of inter-firm collaborations. Conspicuously, besides their high overall interconnectivity, not one of the outperforming clusters shows a strong specialization in either science- or technology-dominated collaborations. As data availability unfortunately does not allow us to control for the locational dimension of collaboration, i.e., whether the partner firm is located within or outside the cluster, we cannot draw any systematic conclusion concerning the inter- and intracluster connectivity.

The inflow of risk capital within and to a cluster is the second aspect of interconnectivity we shed light on. For the nine clusters as well as the remaining part of the country, i.e., the firms outside the clusters, Table 2 provides an overview that distinguishes between VC cash flows on the one hand and the number of deals on the other. First, the table shows that in absolute terms regardless of whether it came from inside or outside the greatest amount of smart money went in and to Munich. Over the period of investigation, more than $€ 1.1$ billion were invested here in 415 single deals. In proportion to the total national VC flows between clusters (column 5) and those coming from outside of that cluster (column 6), in terms of total cash flows as well as number of transactions, these investments account for close to $50 \%$ of the total. That is, nearly half of all intra-cluster financed projects in the German biotechnology industry headed for Munich. Other areas that succeed, although to a smaller extent, in attracting money are the Ruhr area, Berlin, and Heidelberg, attracting 
$14 \%, 13 \%$, and $11 \%$, respectively, from all outside VC flows, i.e., the total national amount of VC less the capital circulated within the clusters themselves (column 6). Each of the remaining clusters attracts only below $2 \%$ of total outside flows.

Table 2: VC flows and deals, 1996-2003

\begin{tabular}{|c|c|c|c|c|c|c|c|c|c|c|c|c|}
\hline \multirow[b]{3}{*}{ Receiver } & \multicolumn{6}{|c|}{ VC Cash flow } & \multicolumn{6}{|c|}{ VC Deals } \\
\hline & $\begin{array}{c}\text { Total } \\
\text { cash- } \\
\text { flow } \\
\text { (Mio.€) }\end{array}$ & $\begin{array}{l}\text { Intra- } \\
\text { cluster } \\
\text { cash- } \\
\text { flow } \\
(\text { Mio } €)\end{array}$ & $\begin{array}{c}\text { National } \\
\text { outside } \\
\text { flows } \\
\text { (Mio } €)\end{array}$ & $\begin{array}{l}\text { Outside } \\
\text { flows } \\
\text { from } \\
\text { abroad } \\
\text { (Mio } € \text { ) }\end{array}$ & $\begin{array}{c}\text { Share } \\
\text { of nat. } \\
\text { intra } \\
\text { flows } \\
(\%)\end{array}$ & $\begin{array}{c}\text { Share } \\
\text { of nat. } \\
\text { outside } \\
\text { flows } \\
\text { (\%) }\end{array}$ & $\begin{array}{l}\text { Total } \\
\text { no. } \\
\text { of VC } \\
\text { deals }\end{array}$ & $\begin{array}{c}\text { No. of } \\
\text { intra } \\
\text { cluster } \\
\text { deals }\end{array}$ & $\begin{array}{c}\text { No. of } \\
\text { out- } \\
\text { side } \\
\text { cluster } \\
\text { deals } \\
\text { (nat.) }\end{array}$ & $\begin{array}{l}\text { No. of } \\
\text { deals } \\
\text { from } \\
\text { abroad }\end{array}$ & $\begin{array}{c}\text { Share } \\
\text { of } \\
\text { nat. } \\
\text { intra } \\
\text { deals } \\
\text { (\%) }\end{array}$ & $\begin{array}{c}\text { Share } \\
\text { of nat. } \\
\text { outside } \\
\text { deals } \\
\text { (\%) }\end{array}$ \\
\hline & (1) & (2) & (3) & (4) & (5) & (6) & (7) & (8) & (9) & (10) & (11) & (12) \\
\hline Munich & 1166.9 & 238.5 & 733.2 & 195.2 & 47.1 & 54.0 & 415 & 120 & 230 & 65 & 36.5 & 49.0 \\
\hline Ruhr area & 333.8 & 42.8 & 184.2 & 106.8 & 8.4 & 13.6 & 89 & 17 & 56 & 16 & 5.2 & 11.9 \\
\hline Heidelberg & 286.3 & 55.9 & 152.3 & 78.1 & 11.0 & 11.2 & 84 & 21 & 44 & 19 & 6.4 & 9.4 \\
\hline Berlin & 244.7 & 45.8 & 171.3 & 33.2 & 9.0 & 12.6 & 114 & 30 & 74 & 13 & 9.1 & 15.8 \\
\hline Hamburg & 43.8 & 15.6 & 9.3 & 18.9 & 3.1 & 0.7 & 9 & 4 & 4 & 1 & 1.2 & 0.9 \\
\hline Göttingen & 42.4 & 6.2 & 31.8 & 4.4 & 1.2 & 2.3 & 17 & 8 & 8 & 1 & 2.4 & 1.7 \\
\hline Stuttgart & 35.3 & 14.9 & 19.3 & 1.2 & 2.9 & 1.4 & 33 & 20 & 12 & 1 & 6.1 & 2.6 \\
\hline Hanover & 15.0 & 3.8 & 9.4 & 1.9 & 0.7 & 0.7 & 12 & 4 & 7 & 1 & 1.2 & 1.5 \\
\hline Rhine/Main & 3.5 & 1.6 & 1.2 & 0.8 & 0.3 & 0.1 & 9 & 3 & 4 & 2 & 0.9 & 0.9 \\
\hline Outside & 179.4 & 81.9 & 45.8 & 51.7 & - & 3,4 & 150 & 102 & 30 & 18 & - & 6.4 \\
\hline Total & 2351,2 & 506,8 & 1357,8 & 492,2 & 100 & 100 & 932 & 329 & 469 & 137 & 100 & 100 \\
\hline
\end{tabular}

Notes: - Investments from the state owned bank 'Technologiebeteiligungsgesellschaft' are not included;-

- In case of joint transactions by two or more syndicating venture capitalists one and the same transaction is repeatedly counted

These findings underline the extraordinary role played by the Bavarian capital city and certainly add to explain the take-off of its biotech industry. Yet apart from this insight, the external linkages to investors seem to be less indicative in predicting cluster success. In particular, if we compare the intra-cluster flows (column 2) to the outside-cluster flows (column 3), we see that the ones which show a relatively high proportion of external flows are not necessarily the industry outperformers. For example, Hanover and Heidelberg display the same intra- to outside-cluster flows ratio of about one to three as Munich; and the low performer Göttingen attracts among the greatest relative proportion of outside flows, namely nearly six times the amount spent within the cluster ${ }^{7}$.

7 To some extent, Göttingen's underperformance concerning this matter can also be attributed to limited data availability. 
Figure 4: VC cash flows within and between German biotech clusters, 1996-2000 and 2001-2003 compared
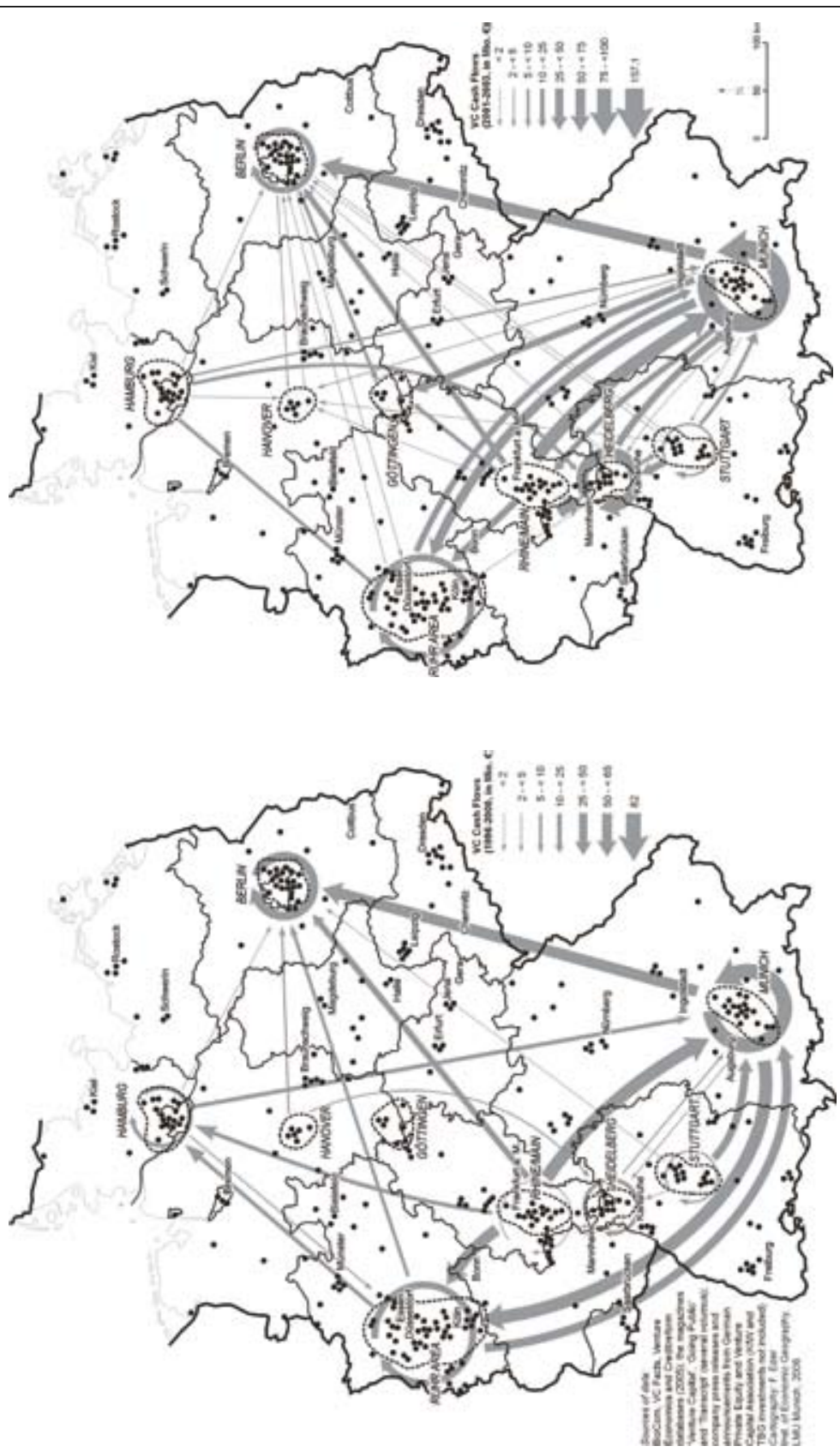
To shed further light on this aspect, Figure 4 displays in dynamic perspective the accumulated cash flows of VC funding within and between the nine German biotech clusters. The two maps distinguish between the time span 1996 to 2000, i.e., from the beginning of our observations up to the crash of the New Economy, and the period 2001 to $2003^{8}$.

Three important findings emerge from the temporally differentiated analysis. First, notwithstanding the overall cooling of VC dynamism, the total amount of investments during the second period exceeds that of the first. The key driver of this development is a significant increase in the mean amount invested (investments between 1996 and 2000 averaged $€ 1.88$ million, from 2001 onwards $€ 2.65$ million), a development which in essence is due to the growing maturity of the receptors, who shift, if successful, from their initial seed and start-up stages towards a more capital-intense expansion stage. Second, we observe that not only has the overall level of VC investments increased, but also the number of linkages between the clusters. With the exception of Hamburg, where the involvement with the interregional VC network remained almost entirely unchanged, all clusters increased their links to external sources of money (and managerial knowledge) on the one hand and their investments into proximately located firms on the other. Most notably, this is the case in Berlin and Stuttgart, where we see an increase of six to 11 and two to seven external links, respectively. Third and finally, concerning the share of intra-regional investments, a pretty variegated picture comes into view: Although the majority of our clusters exhibit a relatively stable proportion of capital invested within them, internal funding decreased in Hamburg and the Rhine/Main area. In contrast, Heidelberg experienced above-average growth concerning this matter.

Taken together, the result of the VC flows mapping exercise is ambiguous if matched with the performance of our clusters. Although all of the three outperforming clusters Munich, Berlin, and the Ruhr area - are intensifying their links to provide finance to and receive capital from other clusters, their respective configurations are relatively dissimilar, with Berlin emerging as one of the receiver clusters but with Munich finding itself within a tight financing net. That is, internal interconnection as well as external linkages can both be regarded as important general cluster features that contribute to the areas' overall success, but add very little to explaining their differing performance levels.

Turning, finally, to public money and governmental grants (compare Table A1 in the appendix), which, apart from triggering significant economic stimuli, are also to be seen as important extra-cluster linkages and potential sources of new ideas and knowledge. Again, and barely astonishing, Munich, Berlin, and the Ruhr area receive by far the greatest slice of the cake. However, this finding must be put into the perspective of the level of economic activity in these localities taken as a whole. Accounting thus for the number of firms as well as for the overall minor level of coverage (take, e.g., the $€ 24$ million governmental means compared to the $€ 1.1$ billion of VC flowing into Munich), again, only

8 The rationale for using these two time spans is straightforward and intuitive. Although the 1990s saw an extremely dynamic development of public equity markets in Germany, including the establishment of Neuer Markt in 1997, the bursting of the New Economy bubble in 2000-01 significantly slowed this dynamic development. 
a small and fairly unsystematic piece can be fit into the puzzle that might explain the detected variance of cluster performance.

In sum, it hitherto can be stated that both a cluster's general composition and its openness respectively its degree of external interconnectivity in terms of collaborations and financial flows provide a certain, but not yet entirely convincing, contribution towards explaining their differing levels of performance. We cannot make any blanket statement on how and to what extent a certain relation or degree of interaction contributes to a cluster's competitiveness. For this reason, the following section turns to the evolutionary paths and individual trajectories of each cluster and investigates the extent to which a cluster's adjustment abilities correspond to its success.

\subsection{EMPIRICAL RESUlTS II: CONVERGENCE AND AdAPTABILITY}

When we address the convergence hypothesis, our third and final analytical step shows changes and movements in each cluster's composition over time. To quantify the extent to which both the level and the direction of change are related to a cluster's performance, Table 4 lists the relative cluster composition index for 1996 and 2003 as the beginning and the end points in our investigation, i.e., the proportion of investors to basic science institutions standardized by the national average9. The third column of Table 4 depicts the change in the composition from 1996 to 2003.

With a change of $55 \%$, the Munich area has undergone the strongest structural change in cluster composition, followed by the Ruhr area with 31\%, Rhine/Main area with 13\%, and Berlin with $12 \%$. If we contrast the cluster types with their respective performance, we find that three of the four most dynamic clusters are the ones that contain the largest number of biotechnology firms. Thus, the intensity of change serves as an indicator of the relationship between dynamics and success. However, the intensity of change does not hold for the Rhine/Main area.

The direction of change represents a second important aspect in this evolutionary investigation. With reference to the results of the cluster composition index, Figure 5 tracks the "movements" of the cluster between 1996 and 2003 in respect of their respective configurations, thus clarifying their varying evolutionary paths: While the clusters Hamburg, Heidelberg, Hanover, and Stuttgart, which have a well-balanced composition of money and ideas in 1996, remain relatively constant, the other five clusters move either towards a more balanced structure (this is the case in Munich, the Ruhr area, and Berlin), or reinforce their financial or scientific dominance (Rhine/Main and Göttingen). 
Table 4: Relative cluster composition 1996 and 2003 compared

\begin{tabular}{lccc}
\hline & \multicolumn{2}{c}{ Cluster Composition Index } & \multirow{2}{*}{ Change Rate } \\
\hline Munich & 1996 & 2003 & $55 \%$ \\
Ruhrarea & 0.386 & 0.597 & $31 \%$ \\
Berlin & 0.437 & 0.572 & $12 \%$ \\
Heidelberg & 1.890 & 1.675 & $4 \%$ \\
Stuttgart & 0.767 & 0.797 & $3 \%$ \\
Hanover & 1.416 & 1.374 & $-1 \%$ \\
Hamburg & 0.885 & 0.879 & $-1 \%$ \\
Göttingen & 0.622 & 0.617 & $-11 \%$ \\
Rhine/Main & 2.950 & 3.274 & $-13 \%$ \\
[outsidecluster] & 0.205 & 0.178 & $0 \%$ \\
\hline \hline
\end{tabular}

Note: * Proportion of basic science institutions to investors/VCs (weighted on national average)

By connecting these paths with cluster performance, the Rhine/Main area and Göttingen suggest that a movement that strengthens the orientation of a cluster is negatively related to cluster performance. We find that the clusters that start off with a well-balanced composition and more or less keep it are the middle field players. In contrast, the outperforming clusters are those three that move from dominant compositions towards less slanted composition. Beginning with investor dominance, Munich and the Ruhr area turn to a more balanced structure. Remarkably, both clusters undertook the most dynamic structural shift and show the highest relative firm growth compared to the other clusters. The German capital Berlin, which locates the largest number of biotech firms over the whole period, moved from its science orientation in 1996 to a less biased composition.

Figure 5: High-performing movers vs. 'captured' colleagues: Types and dynamics in German Biotech clusters

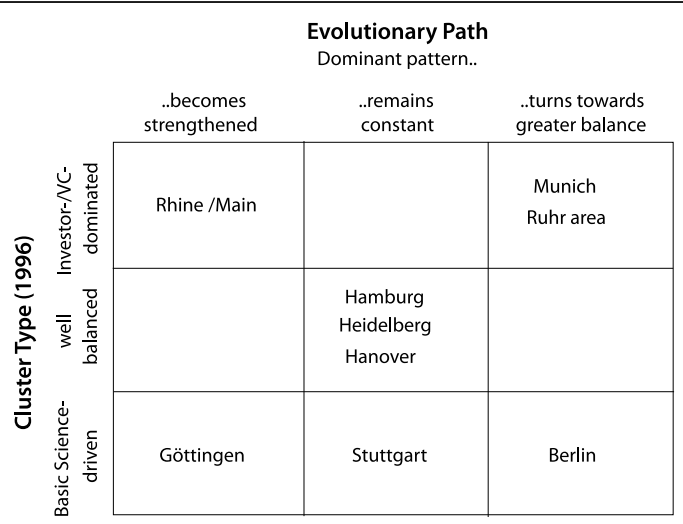


The exercise of tracking the starting position and movement of clusters appears to provide powerful insights in explaining cluster performance. Clusters that start off with a dominant orientation and dynamically manage to change toward a more balanced proportion of capital and science outperform their counterparts. Hence, the dynamic analysis offers a convincing explanation for the success of clusters.

\section{Conclusions}

In this paper we address the evolution of nine biotechnology clusters in Germany between 1996 and 2003. Three different approaches were tested for their power to explain the detected heterogeneity of performance: first, a cluster's composition in terms of the extent to which it hosts science and capital; second, its degree of openness or, in other words, its external linkages to institutions located outside the cluster; and third, its trajectories and ability to adapt its configuration over time.

Although we witnessed the interplay of varying factors as well as a critical mass precondition in all cases, and despite being aware that a "catch-all" recipe that explains different levels of cluster evolution cannot exist, our analysis suggests some strong regularities. The first two ways of reasoning provided some, but not convincing help to further our understanding of cluster performance. Our analysis shows that it is not possible to attribute a certain performance level to a certain cluster type. The analysis of interconnectivity provides ambiguous results. Using interorganizational collaboration as one means of interconnectivity, we find that clusters in which firms are intensely cooperating with both forprofit and nonprofit firms tend to be more successful. In terms of considering financing flows as another means of interconnectivity within and between clusters, - the general interconnection proves to be an important factor for cluster success. However, there is no evidence on the characteristics of involvement (e.g., receiving versus both receiving and giving). That is, without denying their general significance for cluster performance, external linkages do not help to systematically explain the varying success of clusters in breeding high-technology firms.

In contrast, the dynamic perspective (i.e., the view that addresses the extent to which clusters are able to change their composition over time towards a less-slanted structure during the period of investigation) emerges as the key criterion for success. Regardless of whether the cluster is science dominated or money led, those clusters that manage to move to a more balanced composition are the best performing. That is, after a cluster has taken off and established itself in the global competition of innovative locations, the crucial task is to move itself towards a balanced portfolio of science and capital. This result directs our attention to the important but complex task of investigating the factors that set clusters in motion and what keeps them moving. Our primary explorations may provide an avenue for future research on this issue.

However, our findings also have immediate implications for politics, business management, and social science. In political and managerial terms, the constant and ongoing evaluation, intervention in, and direction of cluster composition appear to be a straight- 
forward challenge. The turnover and renewal of cluster composition can maintain the clusters as successful seedbeds for innovative firms.

Regarding the scientific community, when considering firm and cluster performance, our results support the role of a dynamic approach that tracks evolutionary paths. Hence, future research might focus on the extent to which organizations, institutions, and regions are willing to rethink themselves and to undertake the necessary structural adjustments. Although we do not claim to have identified and conceptualized the multilayered mechanisms underlying such movements, or to have answered the causality question (i.e., to what extent external and internal interconnections of firms impact on cluster configuration and vice versa) in comprehensive manner, our hope is that this paper stimulates further explorations that will enable us all to understand the ongoing creative ferment in clusters as social entities. Succeeding evolutionary and comparative studies that inter alia apply a more differentiated performance measure, such as firm turnover or productivity, may offer fruitful contributions and further deepen our knowledge on the interplay of finance, innovation, and space. 


\section{ApPendiX}

Table A1: Governmental financial means granted to biotechnology firms, 1996-2003

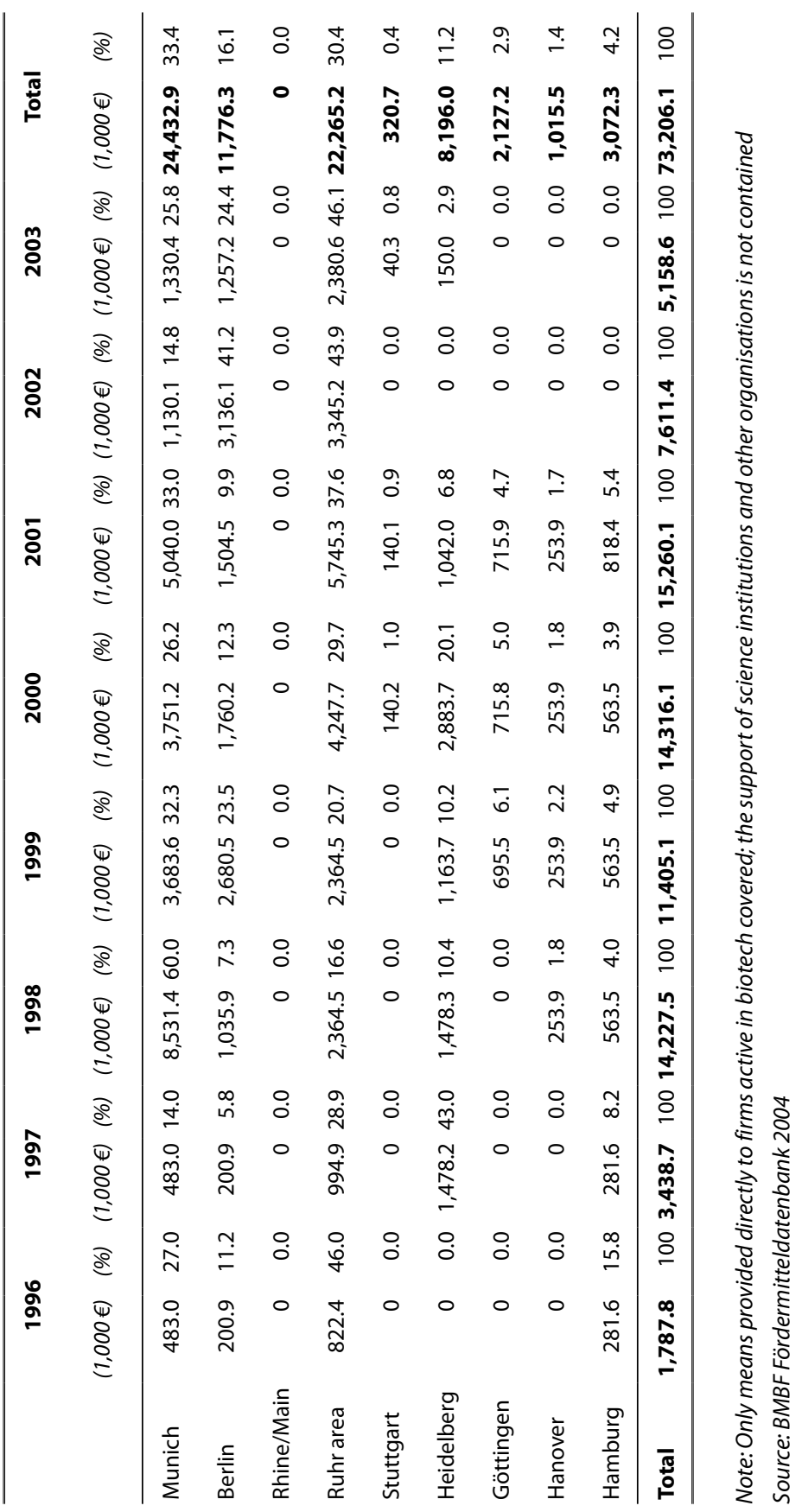




\section{References}

Aharonson, Barak, Joel Baum and Maryann P. Feldman (2004), Industrial clustering and the returns to inventive activity: Canadian biotechnology firms, 1991-2000, DRUID Working Paper No. 04-03.

Audretsch, David and Paula E. Stephan (1996), Company-scientist locational links: The case of biotechnology, American Economic Review 86, 641-652.

Audretsch, David and Maryann P. Feldman (1996), R\&D spillovers and the geography of innovation and production, American Economic Review 86, 630-640.

Bathelt, Harald, Anders Malmberg, and Peter Maskell (2004), Clusters and knowledge: Local buzz, global pipelines and the process of knowledge creation, Progress in Human Geography 28, 31-56.

BioCom (2004), BioTechnologie - Das Jahr-und Adressbuch, Berlin: BioCom AG. (also for the years 1995-2003)

Bundesministerium für Bildung und Forschung (2004), Förderdatenbank von BMBF/BMWA.

Bresnahan, Timothy, Alfonso Gambardella, and Annalee Saxenian (2001), 'Old economy' inputs for 'new economy' outcomes: Cluster formation in the new Silicon Valley, Industrial and Corporate Change 10, 835-860.

Casamatta, Catherine (2003), Financing and advising: Optimal financial contracts with venture capitalists, The Journal of Finance 58, 2059-2085.

Cairncross, Frances (1997), The death of distance, London: Orion.

Coyle, Diane (1997), The weightless world. Strategies form managing the digital economy, London: Capstone.

Clark, Gordon L. and Dariusz Wójcik (2005), Path dependence and financial markets: The economic geography of the German model, 1997-2003, Environment and Planning A 30, 1769-1791.

DiMaggio, Paul J. and Walter W. Powell (1983), The iron cage revisited: Institutional isomorphism and collective rationality in organizational fields, American Sociological Review 48, 174-190.

DiMasi, Joseph, Ronald Hansen, and Henry Grabowski (2003), The price of innovation: new estimates of drug development costs, Journal of Health Economics 22, 151-185.

Ernst \& Young (2001), Biotech in Germany, Stuttgart: Ernst \& Young.

Feldman, Maryann P. (1994), The geography of innovation, Boston: Kluwer Academic Publishers.

Feldman, Maryann P. and Richard Florida (1994), The geographic sources of innovation: Technological infrastructure and product innovation in the united states, Annals of the Association of American Geographers 84, 210-229.

Grabher, Gernot (1993), The embedded firm. On the socioeconomics of industrial networks, London: Routledge.

Häussler, Carolin (2005), Inter-firm collaboration: Valuation, contracting, and firm restructuring, Wiesbaden: Gabler.

Häussler, Carolin (2007), Proactive versus reactive M\&A activities in the biotechnology industry, Journal of High Technology Management Research 17, 109-123.

Häussler, Carolin and Dietmar Harhoff (2007), National systems of innovation - Convergence in British and German biotechnology? Working Paper, Munich School of Management.

Jaffe, Adam (1989), Real effects of academic research, American Economic Review 79, 957-970.

Klagge, Britta and Ron Martin (2005), Decentralized versus centralized financial systems: is there a case for local capital markets?, Journal of Economic Geography 5, 387-421.

Leamer, Edward and Michael Storper (2001), The economic geography of the internet age, Journal of International Business Studies 32, 641-665.

Morgan, Kevin (2004), The exaggerated death of geography: learning, proximity and territorial systems, Journal of Economic Geography 4, 3-21.

Maskell, Peter and Anders Malmberg (1999), Localised learning and industrial competitiveness, Cambridge Journal of Economics 23, 167-185.

Ohmae, Kenichi (1990), The borderless world: Power and strategy in the inter-linked economy, New York: Harper Business. 
Owen-Smith, Jason and Walter W. Powell (2006), Accounting for emergence and novelty in Boston and Bay Area Biotechnology, in: Pontus Braunerhjelm and Maryann Feldman (eds.), Cluster Genesis: The emergence of technology cluster and their implication for government policies, Oxford: Oxford University Press.

Porter, Michael (2000), Locations, clusters, and company strategy, in: Gordon Clark, Maryann Feldman P., and Meric Gertler (eds.), The Oxford Handbook of Economic Geography, Oxford: Oxford University Press, 253-274.

Porteous, David J. (1995), The geography of finance: Spatial dimensions of intermediary behaviour, Aldershot: Avebury.

Powell, Walter W., Kenneth Koput, James Bowie, and Laurel Smith-Doerr (2002), The spatial clustering of science and capital: Accounting for biotech firm-venture capital relationships, Regional Studies 36, 291-305.

Prevezer, Martha (1997), The dynamics of industrial clustering in biotechnology, Small Business Economics 9, 225271.

Quah, Danny (1997), Increasingly weightless economies, Bank of England Quarterly Bulletin 2, 49-56.

Rodríguez-Pose, Andrés and Hans-Martin Zademach (2006), Industry Dynamics in the German Merger and Acquisition Market, Tijdschrift voor Economische en Sociale Geografie 97, 296-313.

Saxenian, Annalee (1994), Regional advantage: Culture and competition in Silicon Valley and Route 128, Cambridge: Cambridge University Press.

Storper, Michael and Anthony Venables (2004), Buzz: The economic force of the city, Journal of Economic Geography 4, 351-370.

Stuart, Toby, Ha Hoang, and Ralph Hybels (1999), Interorganizational endorsements and the performance of entrepreneurial ventures, Administrative Science Quarterly 44, 315-349.

Zademach, Hans-Martin (2005), Spatial dynamics in the markets of $M \mho A$, Essays on the geographical determination and implications of corporate takeovers and mergers in Germany and Europe (Wirtschaft und Raum, Band 12), Munich: Herbert Utz.

Zeller, Christian (2001), Clustering biotech: A recipe for success? Spatial patterns of growth of biotechnology in Munich, Rhineland and Hamburg, Small Business Economics 17, 123-141.

Zucker, Lynne, Michael Darby, and Marilynn Brewer (1998), Intellectual human capital and the birth of US biotechnology enterprises, American Economic Review 88, 290-306. 


\section{Order form Order now!}

Verlagsgruppe Handelsblatt GmbH

Abo-Service Ausland

Postfach 102753

40018 Düsseldorf

Germany

Fon: 00492118871730

Fax: 00492118871738

e-mail: abo-service@vhb.de

Internet: www.sbr-online.com

simply the best research.

\section{Use this form to order your free sample copy and to subscribe to sbr!}

\section{Free sample copy}

$\square$ Please send me a free sample copy of sbr PB-ZFSBRPH1

\section{Subscription}

$\square$ Open ended subscription*

$\square$ One-Year subscription

PB-ZFSBRO15

* In case of open-ended subscription an invoice will be issued at the end of each subscription year to cover the next year. Cancellation within a period of at least 21 days before the new subscription year begins.

\section{Subscription rates ${ }^{\star *}$}

Schmalenbach Business Review (sbr),

ISSN: 1439-2917, Quaterly

Institutions:

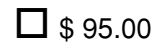

$\square £ 60.00$

$\square € 91.00$ Individuals:

$\square \$ 48.00$

$\square £ 30.00$

$\square € 45.00$

Students*:

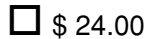

$£ 50.00$

$€ 21.00$

* Student rate only accepted with copy of validated ID.

** Postage rates are - depending on the currency you want to be charged in $-\$ 14, £ 8, € 12$.

\section{Payment}

Payment is due within 14 days on receipt of invoice. You will receive the invoice directly from Verlagsgruppe Handelsblatt $\mathrm{GmbH}$ in Düsseldorf.

\section{Address}

Institute/Company

Position/Department

First and Surname

Street and Number

Zip Code

City

State

Country

Fon

Fax

e-mail

X

Signature Date

